\title{
Untwisting dystonia: stepping-up genetics, shifting pathophysiology, and strategizing care
}

\author{
Raymond L. Rosales ${ }^{1,2} \cdot$ Ana Westenberger ${ }^{3}$
}

Accepted: 19 April 2021 / Published online: 30 April 2021

(c) The Author(s), under exclusive licence to Springer-Verlag GmbH Austria, part of Springer Nature 2021

Dystonia belongs to the most common movement disorders, with a prevalence which increases with age (Steeves et al. 2012) and may reach $>700$ per 100,000 in individuals above 50 years of age (Müller et al. 2002). Although the original use of the term dystonia likely referred to a single disorder (Oppenheim 1911; Klein and Fahn 2013), in the last several decades, it became clear that it actually represents a hypernym that covers a large number of clinically and etiologically different conditions. Furthermore, in recent years, the development and wide availability of new technologies and resources allowed for a better understanding of the pathological processes preceding dystonic symptoms in patients. The reduction of what used to be decades of efforts in finding new dystonia genes to mere months represents a particularly illustrative example of these contemporary advances. In parallel, our comprehension of various aspects of dystonia has considerably improved treatment and care options for patients.

In light of the aforementioned progress, this special issue aims at providing the most current account of dystonia genetics, pathophysiology, and care. The introductory article updates on the definition and nomenclature of dystonia as well as on the two classification axes (clinical and etiological) (Grütz and Klein 2021). The following contributions focus on genetic aspects of dystonia by reviewing the present knowledge of hereditary isolated (Domingo et al. 2020), combined (Weissbach et al. 2020), complex (Herzog

Raymond L. Rosales

rlrosales@ust.edu.ph

1 The Department of Neurology and Psychiatry and The Neuroscience Institute, University of Santo Tomas Medical Faculty and University Hospital, Manila, Philippines

2 Movement Disorders and Clinical Neurophysiology, Institute for Neurosciences, St. Luke's Medical Center, Quezon City, Philippines

3 Institute of Neurogenetics, University of Lübeck, Lubeck, Germany et al. 2020), and paroxysmal disease forms (Liao et al. 2021), and the relevance of genetic testing (Pozojevic et al. 2021). Importantly, through the expedite uncovering of the genetic basis of monogenic dystonias, new molecular mechanisms underlying the disease process have emerged and indicated several areas of functional convergence among the relevant proteins (Gonzalez-Latapi et al. 2021).

Moving to clinical care, the underpinnings from functional neuroanatomy (Brüggemann 2021) and neurophysiology (Kaňovský et al. 2021) serve as useful guides in planning diagnostic and therapeutic approaches in dystonia. Various clinical neurophysiological techniques have been applied to assess dystonia, essentially lending support to dystonia, gleaned as a 'network disorder,' and including the recent focus on cerebellar networks. In treatment, the leverage of oral pharmacotherapy (Sy and Fernandez 2021) is hinged on accurate diagnosis, early detection, and bearing in mind the treatable causes. Let alone that these oral pharmacologic therapies may be complemented by chemodenervation therapy with botulinum neurotoxin injections (Dressler et al. 2020). Precise muscle targeting, be it instrument-guided, proper timing, or a goal-directed dosing regimen, are the cornerstones of safe and effective botulinum toxin applications.

Functional surgery (Kim and Jeon 2021) with deep brain stimulation (DBS) targeting the globus pallidus interna has favorable outcomes, especially in idiopathic and inherited isolated generalized/segmental dystonia. In the absence of fixed contractures or if pharmacologic therapies fail, DBS shows good outcomes, especially when considered earlier and being mindful that the genotype may drive DBS results. Neurorehabilitation (Bradnam et al. 2020) has its place in dystonia care, however, the complexity of having non-motor symptoms on top of the dominant motor symptoms lends support for the implementation of multi-/inter-disciplinary team approach. New modality approaches in dystonia care (Oyama and Hattori 2021) may complement the aforementioned therapies, along a dual axis of non-invasive 
neuromodulation and of wearable devices or motion capturing systems for a quantitative assessment of dystonia.

This present compilation ends with a dystonia example, $\mathrm{X}$-linked dystonia-parkinsonism (XDP), a hereditary neurodegenerative disorder which is the focus of our current collaborative clinical and genetic research. XDP is largely prevalent among males in the Philippine Island of Panay, though cases are now reported from other countries, but only to be found with a female carrier Filipino mother. To 'untwist XDP,' we are perhaps reaching a new threshold in its understanding that ranges from being a model disease for pathophysiologic formulations, to a stepped-up genetics, and to improve strategized clinical care. From an updated clinical perspective ( $\mathrm{Ng}$ et al. 2021), data regarding the motor and non-motor features of XDP, DBS outcomes, and the utility of the XDP-Movement Disorder Society of the Philippines (MDSP)-rating scale have been tackled. Recent years saw striking progress elucidating the genetic basis of XDP as well as candidate disease mechanisms in patient-derived cellular models, yet the in vivo neural substrates that give rise to XDP remain a gap. In the latter context, a platform for brain banking to establish a human tissue repository for XDP studies may complement these basic and translational studies (Fernandez-Cerado et al. 2021). In the Capiz province of Panay island, where access to medical and laboratory facilities is limited, the brain banking implementation process poses distinct challenges in capturing this specific population. The said platform presents an algorithm for XDP, ranging from donor recruitment to consent to tissue collection, processing, and finally storage.

One of the important goals of this special issue is to serve as a comprehensive and inspirational reminder of what has been achieved in dystonia research and patient care to date. In addition, we hope that it will provide an impetus for the scientific community and, in particular, for students, young researchers, and movement disorders fellows to continue the dedicated work towards understanding and conquering dystonia.

We are very grateful to all the colleagues who contributed to the development of this special issue.

\section{References}

Bradnam LV, Meiring RM, Boyce M, McCambridge A (2020) Neurorehabilitation in dystonia: a holistic perspective. J Neural Transm. https://doi.org/10.1007/s00702-020-02265-0

Brüggemann $\mathrm{N}$ (2021) Contemporary functional neuroanatomy and pathophysiology of dystonia. J Neural Transm. https://doi.org/10. 1007/s00702-021-02299-y
Domingo A, Yadav R, Ozelius LJ (2020) Isolated dystonia: clinical and genetic updates. J Neural Transm. https://doi.org/10.1007/ s00702-020-02268-x

Dressler D, Adib Saberi F, Rosales RL (2020) Botulinum toxin therapy of dystonia. J Neural Transm. https://doi.org/10.1007/ s00702-020-02266-z

Fernandez-Cerado C, Legarda GP, Velasco-Andrada MS et al (2021) Promise and challenges of dystonia brain banking: establishing a human tissue repository for studies of X-Linked Dystonia-Parkinsonism. J Neural Transm. https://doi.org/10.1007/ s00702-020-02286-9

Gonzalez-Latapi P, Marotta N, Mencacci NE (2021) Emerging and converging molecular mechanisms in dystonia. J Neural Transm. https://doi.org/10.1007/s10545-018-0205-0

Grütz K, Klein C (2021) Dystonia updates: definition, nomenclature, clinical classification, and etiology. J Neural Transm. https://doi. org/10.1007/s00702-021-02314-2

Herzog R, Weissbach A, Bäumer T, Münchau A (2020) Complex dystonias: an update on diagnosis and care. J Neural Transm. https:// doi.org/10.1007/s00702-020-02275-y

Kaňovský P, Rosales R, Otruba P et al (2021) Contemporary clinical neurophysiology applications in dystonia. J Neural Transm. https://doi.org/10.1007/s00702-021-02310-6

Kim H-J, Jeon B (2021) Arching deep brain stimulation in dystonia types. J Neural Transm. https://doi.org/10.1007/ s00702-021-02304-4

Klein C, Fahn S (2013) Translation of Oppenheim's 1911 paper on dystonia. Mov Disord 28:851-862

Liao J, Salles P, Shuaib U, Fernandez HH (2021) Genetic updates on paroxysmal dyskinesias. J Neural Transm. https://doi.org/10.1007/ s00702-021-02335-x

Müller J, Kiechl S, Wenning GK et al (2002) The prevalence of primary dystonia in the general community. Neurology 59:941-943. https://doi.org/10.1212/01.WNL.0000026474.12594.0D

Ng AR, Jamora RDG, Rosales RL (2021) X-linked dystonia Parkinsonism: crossing a new threshold. J Neural Transm. https://doi.org/ $10.1007 / \mathrm{s} 00702-021-02324-0$

Oppenheim H (1911) About a rare spasm disease of childhood and young age (dysbasia lordotica progressiva, dystonia musculorum deformans). Neurol Cent 30:1090-1107

Oyama G, Hattori N (2021) New modalities and directions for dystonia care. J Neural Transm. https://doi.org/10.1007/ s00702-020-02278-9

Pozojevic J, Beetz C, Westenberger A (2021) The importance of genetic testing for dystonia patients and translational research. J Neural Transm. https://doi.org/10.1007/s00702-021-02329-9

Steeves TD, Day L, Dykeman J et al (2012) The prevalence of primary dystonia: a systematic review and meta-analysis. Mov Disord 27:1789-1796. https://doi.org/10.1002/mds.25244

Sy MAC, Fernandez HH (2021) Dystonia and leveraging oral pharmacotherapy. J Neural Transm. https://doi.org/10.1007/ s00702-021-02339-7

Weissbach A, Saranza G, Domingo A (2020) Combined dystonias: clinical and genetic updates. J Neural Transm. https://doi.org/10. 1007/s00702-020-02269-w

Publisher's Note Springer Nature remains neutral with regard to jurisdictional claims in published maps and institutional affiliations. 